\title{
Resting state EEG abnormalities in autism spectrum disorders
}

\author{
Jun Wang ${ }^{1 *+}$, Jamie Barstein ${ }^{1 \dagger}$, Lauren E Ethridge ${ }^{1}$, Matthew W Mosconi ${ }^{1,2}$, Yukari Takarae ${ }^{1}$ and John A Sweeney ${ }^{1,2,3}$
}

\begin{abstract}
Autism spectrum disorders (ASD) are a group of complex and heterogeneous developmental disorders involving multiple neural system dysfunctions. In an effort to understand neurophysiological substrates, identify etiopathophysiologically distinct subgroups of patients, and track outcomes of novel treatments with translational biomarkers, EEG (electroencephalography) studies offer a promising research strategy in ASD. Resting-state EEG studies of ASD suggest a U-shaped profile of electrophysiological power alterations, with excessive power in low-frequency and high-frequency bands, abnormal functional connectivity, and enhanced power in the left hemisphere of the brain. In this review, we provide a summary of recent findings, discuss limitations in available research that may contribute to inconsistencies in the literature, and offer suggestions for future research in this area for advancing the understanding of ASD.
\end{abstract}

Keywords: Autism, Resting-state, EEG, Electroencephalography

\section{Review}

\section{Introduction}

Autism spectrum disorders (ASD) are characterized by social and communication impairments, and by restricted and stereotyped behaviors [1]. ASD affect approximately 1 in 88 children and 1 in 54 males [2]. These disorders are highly heritable, with estimates ranging from 70 to $90 \%$ [3], and are known to have a high recurrence rate in siblings (10 to $20 \%$ [4]), yet, progress in identifying pathophysiological and etiological mechanisms has been limited.

It is likely that there are many causes of ASD. Several single-gene disorders (for example, Fragile $\mathrm{X}$, tuberous sclerosis) and rare copy number variants (CNVs) (for example, 16p11 deletions, 15q13 duplications) appear to be strongly associated with ASD, but genetic syndromes, mutations, and single-gene etiologies account for only 10 to $20 \%$ of ASD cases, and many individuals with these genetic syndromes do not have ASD [5]. The majority of affected individuals appear to have more complex underlying genetic and epigenetic abnormalities, involving highly penetrant yet undiscovered rare mutations, or

\footnotetext{
* Correspondence: jun.wang@utsouthwestern.edu

${ }^{\dagger}$ Equal contributors

'Department of Psychiatry, University of Texas Southwestern, Dallas, TX, USA Full list of author information is available at the end of the article
}

combinations of less penetrant and more common variants. The highly variable clinical presentation of ASD reflects this heterogeneity. Affected individuals vary greatly in the course of the disorder (around a quarter show significant developmental regression), associated medical conditions, behavioral challenges (for example, sensory issues, hyperactivity), and degree of intellectual impairment [6,7].

Many studies have attempted to characterize the neural system abnormalities associated with ASD $[8,9]$. Post-mortem studies have most consistently noted abnormalities in the limbic system and cerebellum [10]. Neuroimaging studies have identified abnormalities in brain and head size, and in cerebellum and limbic structures [11-13], with some individuals showing a pattern of early brain overgrowth [11,14-16]. Functional MRI (fMRI) studies have reported abnormalities in individuals with ASD when performing various tasks involving language comprehension [17], working memory [18], face recognition [19,20], and eye movements [9]. Compared with typically developing subjects, individuals with ASD usually express a diffuse network pattern with diminished activity in task-related regions and increased activity in task-unrelated regions $[9,20,21]$. When there is no task involved, individuals with ASD show functional underconnectivity in anterior-posterior connections [22] and reduced connectivity involving the medial prefrontal

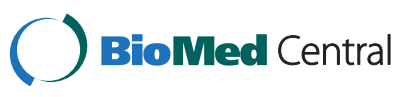


cortex and the left angular gyrus [23]. Moreover, a lack of deactivation in task-related regions during rest has also been reported in individuals with ASD [24]. Although post-mortem and structural MRI studies of ASD have provided promising insights, abnormalities often fail to provide a direct link to the clinical symptomatology of the disorder, with few exceptions $[13,25]$, a challenge for which neurophysiological studies offer advantages.

Electroencephalography (EEG), which primarily measures neurophysiological changes related to postsynaptic activity in the neocortex [26], has proven to be a powerful tool for studying complex neuropsychiatric disorders [27-30]. EEG has been the primary measure used to capture and characterize epileptiform and abnormal paroxysmal activity through the detection of focal spikes, which occur with increased frequency in ASD [31,32]. Resting EEG studies have shown that $20 \%$ of individuals with ASD show epileptiform discharges at rest, typically without the presence of clinical seizures [33,34]. Higher rates of epileptiform activity have also been reported in sleep studies; for example, Chez, et al. [35] reported that $61 \%$ of individuals with ASD and no clinical history of seizures displayed epileptiform abnormalities.

The most common way to characterize resting EEG is by breaking down the oscillatory patterns into bands of frequencies that share physiological properties. The typical clinically relevant frequency bands of EEG range from 0.3 to $100 \mathrm{~Hz}$. Within the scope of the current paper, we focus on five frequency bands ranging from 1 to $100 \mathrm{~Hz}$ : delta ( 1 to $3 \mathrm{~Hz}$ ), theta ( 4 to $7 \mathrm{~Hz}$ ), alpha ( 8 to $12 \mathrm{~Hz}$ ), beta $(13$ to $35 \mathrm{~Hz})$, and gamma $(>35 \mathrm{~Hz})$. These historically documented frequency bands have attracted rapidly growing interest in clinical and cognitive neuroscience fields, and are believed to govern different cognitive processes [36]. Delta dominates deep sleep, and is thought to underlie the event-related slow waves seen in tasks for detection of attention and salience [37]. Theta is most commonly studied in relation to memory processes [38]. Alpha waves are present in relaxed awake individuals, and are associated with precise timing of sensory and cognitive inhibition [39]. Beta waves are associated with alertness, active task engagement, and motor behavior [40]. Finally, gamma waves, present during workingmemory matching [41] and a variety of early sensory responses, are believed to facilitate feature binding in sensory processing [42,43].

Additionally, EEG recordings can be used to assess functional connectivity between different brain regions over time via EEG coherence, and quantitative measurement of the relationship of frequency spectra between two EEG signals [44]. This advantageous feature can further our understanding of the impaired interactions between brain regions of individuals with ASD that have been suggested by functional MRI studies [45-51].

\section{Advantages of resting-state EEG for studying brain dysfunction in ASD}

Resting-state EEG studies are used to monitor brain activity in the absence of overt task performance or sensory stimulation. These measurements can identify abnormalities for which evoked potential studies, the most widely used approach in EEG research with ASD, are not well suited [52]. Indeed, task-dependent changes in brain function are difficult to interpret without fundamental knowledge of functional differences in individuals with ASD at rest. In task-based evoked potential studies, only time-locked neural responses to events of interest are studied; all other spontaneous activity is typically considered background noise [53-55]. Multiple studies have suggested that the brain is a system that operates intrinsically, with intrinsic resting-state integration. External sensory information interacts with, rather than determines, the operation of brain systems [55-57]. For example, many studies have shown that pre-stimulus EEG activities predict the event-related potentials for visual stimuli [58] or motor responses [59].

There are also several practical advantages of using EEG to study brain function in developmental disorders such as ASD. Compared with MRI, EEG can be used across a wider range of age groups and developmental abilities to study brain physiology, has a higher relative tolerance for movement, has higher temporal resolution, is more clinically available, and can be used to collect repeated measurements because (compared with positron emission tomography) it is non-invasive. Resting-state approaches do not require subjects to make a response. This element is particularly promising for studying more severely impaired and/or younger patients who may not be able to perform tasks accurately because of cognitive, physical, or developmental challenges. This is crucial for studying the abnormal maturational trajectory in ASD through early childhood. The literature on restingstate EEG in healthy individuals shows increased alpha power and coherence in individuals with ASD [60], as well as reduced power in low-frequency bands (delta, theta) [61] in adults relative to children. These findings reflect maturation of long-range cortico-cortical connections into adulthood.

Quantitative EEG of resting-state data also has promise as an approach for monitoring treatment outcomes. Pineda et al. [62] reported that individuals with ASD who received neurofeedback training on controlling neural oscillatory activity in the alpha or mu band displayed decreased mu power and coherence, as well as improved performance on an attention test and decreased scores on the Autism Treatment Evaluation Checklist [63]. Neurofeedback training (aiming at reducing theta activity while increasing beta activity) has also been reported to improve executive test performance in indi 
viduals with ASD (including attentional control, cognitive flexibility, and goal-setting) for up to 12 months $[64,65]$.

Despite these unique advantages, relatively few studies have used EEG to study resting-state brain alterations in ASD. In the present article, we review the existing literature on EEG resting-state abnormalities in ASD, discuss potential causes of inconsistencies between studies, and offer suggestions for future studies utilizing resting-state EEG to understand the pathophysiological mechanisms involved in ASD.

\section{Resting-state EEG findings in ASD}

Early resting-state EEG studies of ASD failed to identify consistent patterns of atypical neural activity [66-70]. The recognized prevalence of EEG abnormalities in patients varied greatly between studies, which may be attributable to the lack of standardized diagnostic approaches at the time or to limitations in EEG recording technology (for example, small numbers of electrodes) and analysis (for example, qualitative judgments, different approaches to quantification). We limited our review to EEG studies that used spectral analysis to investigate activity in different power bands and coherence between hemispheres and brain regions (Table 1 ).

\section{Abnormal power}

EEG power can be measured as either relative power or absolute power. Relative power is the amount of EEG activity in an individual frequency band divided by the amount of activity in all frequency bands. Absolute power is the amount of EEG activity in one band independent of activity in other bands. Relative power thus reflects the relationship between frequency bands, but does not yield an indication of the degree to which abnormal electrophysiological activity is present in a specific frequency band. Studies of ASD vary widely in the extent to which they present absolute power findings (Table 1), so interpretation of atypical inter-relationships between different frequency bands (relative power) can be advantageous for comparing frequency bands, but also confounds measurement of activity in the target band within any alterations that may occur in other frequency bands. Absolute power is in many ways preferable for developing an understanding of electrophysiological alterations in ASD, and for the interpretation of differences in relative power in this population [71].

In addition to differences between studies in approaches for characterizing EEG activity, studies of ASD are also confounded by the extreme behavioral and putative neurophysiological heterogeneity that characterizes this disorder. Studies vary widely in the demographic characteristics of their samples, and factors such as the age of subjects studied, and whether or not subjects with intellectual disability (ID) were included, may significantly affect study findings. Despite these important concerns, a relatively consistent and unique profile of electrophysiological abnormalities has emerged from resting-state EEG studies, which appears to be present across diverse patient populations. Specifically, excessive power at low-frequency (delta, theta) and high-frequency (beta, gamma) bands, but reduced power in the middle-range frequency band (alpha) (Figure 1) has been found at all stages of development and in children with and children without comorbid ID [72-75]. The excess in delta power has been found in both relative [72,73] and absolute [73-75] powers, and in multiple brain regions, including the dorsal midline, parietal, right temporal [73] and frontal cortical $[74,75]$ areas, suggesting a widely distributed pattern of abnormality [72]. Similarly, enhanced low frequency relative $[76,77]$ and absolute $[75,78]$ theta $(4$ to $7 \mathrm{~Hz}$ ) activity has been seen in both adults [76,78] and children [75,77] with ASD, primarily in the frontal and right posterior cortex. Enhanced power has also been reported in high-frequency relative beta (13 to $35 \mathrm{~Hz}$ ) and absolute gamma (>35 Hz) bands in both adults [76] and children $[77,79]$ with ASD. Within the higher-frequency bands, the most significant alterations have been found in gamma power over occipital, parietal [76] and midline $[77,79]$ regions.

In contrast to the excess power displayed in low-frequency (delta, theta) and high-frequency (beta, gamma) bands, individuals with ASD show reduced relative $[72,73,76]$ and absolute [80] power in middle-range (alpha) frequencies across many brain regions [72,73], including the frontal, [76,80], occipital, parietal [76], and temporal [80] cortex. This pattern indicates a Ushaped profile of electrophysiological power alterations in ASD in which the extremities of the power spectrum are abnormally increased, while power in the middle frequencies is reduced. Available evidence for this model is mostly supportive, but more hypothesisdriven work is needed to confirm and validate it.

We speculate that the etiology for this U-shaped profile may be attributed in part to abnormal functioning of gamma-aminobutryic acid (GABA)ergic tone in inhibitory circuitry, which influences the functional and developmental plasticity of the brain and is thought to modulate power in high-frequency and low-frequency bands while increasing the power of middle-range frequencies (alpha band) [81]. Activity in the gamma band that is visible in EEG seizure recordings has been linked to impairment of dendritic GABAergic inhibition [82]. However, increasing GABA concentration by administrating the GABA antagonist vigibatrin has been shown to increase resting delta power in both rats [83] and humans [84], suggesting that a simple decrease in GABA does not fully explain the U-shaped spectral profile in ASD. For example, thalamocortical delta oscillations are produced by an 
Table 1 Power and coherence effects in ASD compared with typically developing individuals

\begin{tabular}{|c|c|c|c|}
\hline Frequency band & Brain region(s) & Effect & $\operatorname{Ref}(s)$ \\
\hline & & Absolute power & \\
\hline \multirow[t]{4}{*}{ Delta } & Frontal & Enhanced & {$[74,75]$} \\
\hline & Frontal & Reduced & {$[77,80]$} \\
\hline & Central/parietal & Enhanced & [73] \\
\hline & Temporal & Reduced & [80] \\
\hline \multirow[t]{4}{*}{ Theta } & Frontal/prefrontal & Enhanced & {$[75,78]$} \\
\hline & Frontal & Reduced & [80] \\
\hline & Temporal & Reduced & {$[80]$} \\
\hline & Parietal & Reduced & [80] \\
\hline \multirow[t]{6}{*}{ Alpha } & All regions & No effect & {$[77,105]$} \\
\hline & Frontal/prefrontal & Reduced & [80] \\
\hline & Frontal & Enhanced & [106] \\
\hline & Parietal & Enhanced & [106] \\
\hline & Central & Enhanced & [106] \\
\hline & Temporal & Reduced & {$[80]$} \\
\hline \multirow[t]{2}{*}{ Beta } & All regions & No effect & {$[80]$} \\
\hline & All regions & Reduced & [77] \\
\hline \multirow[t]{2}{*}{ Gamma } & Midline/central and parietal & Enhanced & {$[79]$} \\
\hline & & Relative power & \\
\hline \multirow[t]{3}{*}{ Delta } & All regions & Enhanced & [72] \\
\hline & Frontal & Reduced & [77] \\
\hline & Central/parietal & Enhanced & [73] \\
\hline \multirow[t]{2}{*}{ Theta } & Frontal/prefrontal & Enhanced & {$[76]$} \\
\hline & Right posterior & Enhanced & [77] \\
\hline \multirow[t]{4}{*}{ Alpha } & All regions & Reduced & {$[72,73]$} \\
\hline & All regions & No effect & [77] \\
\hline & Frontal/prefrontal & Reduced & [76] \\
\hline & Occipital/parietal & Reduced & {$[76]$} \\
\hline \multirow[t]{2}{*}{ Beta } & Occipital/parietal & Enhanced & {$[76]$} \\
\hline & & Coherence & \\
\hline \multirow[t]{7}{*}{ Delta } & Short/long intrahemispheric & Reduced & {$[77]$} \\
\hline & Lateral-frontal intrahemispheric & Enhanced & [118] \\
\hline & Middle frontal & Reduced & [118] \\
\hline & Occipital & Reduced & [118] \\
\hline & Frontal & Reduced interhemispheric & [77] \\
\hline & Temporal & Reduced interhemispheric & [77] \\
\hline & Central/parietal/occipital & Reduced interhemispheric & {$[77]$} \\
\hline \multirow[t]{5}{*}{ Theta } & Short/long intrahemispheric & Reduced & {$[77,119]$} \\
\hline & Short/long intrahemispheric & Enhanced & {$[76]$} \\
\hline & Frontal & Reduced interhemispheric & {$[77]$} \\
\hline & Temporal & Reduced interhemispheric & [77] \\
\hline & Central/parietal/occipital & Reduced interhemispheric & [77] \\
\hline \multirow[t]{2}{*}{ Alpha } & Frontal & Reduced & [76] \\
\hline & Between frontal and all other regions & Reduced & [76] \\
\hline
\end{tabular}


Table 1 Power and coherence effects in ASD compared with typically developing individuals (Continued)

\begin{tabular}{|c|c|c|c|}
\hline & Temporal & Reduced interhemispheric & [77] \\
\hline & Short/long intrahemispheric & Reduced & [119] \\
\hline \multirow[t]{4}{*}{ Beta } & Central/parietal/occipital & Reduced interhemispheric & [77] , \\
\hline & Frontal-temporal & Reduced & [119] \\
\hline & Short/long intrahemispheric & Reduced & [119] \\
\hline & \multicolumn{3}{|c|}{ Hemispheric asymmetry } \\
\hline \multirow[t]{9}{*}{ Delta } & Frontal & Reduced power in left hemisphere & [80] \\
\hline & Frontal & Enhanced power in left compared with right hemisphere & [74] \\
\hline & Temporal & Reduced power in left hemisphere & [80] \\
\hline & Temporal & Enhanced power in left compared with right hemisphere & [74] \\
\hline & Parietal & Enhanced power in left compared with right hemisphere & [74] \\
\hline & Posterior-temporal & Enhanced power in left compared with right hemisphere & [72] \\
\hline & Central & Enhanced power in left compared with right hemisphere & [72] \\
\hline & Occipital & Enhanced power in left compared with right hemisphere & [72] \\
\hline & Occipital & No difference between left and right hemispheres & [105] \\
\hline \multirow[t]{10}{*}{ Theta } & Frontal & Reduced power in left hemisphere & [80] \\
\hline & Frontal & Enhanced power in left compared with right hemisphere & {$[74,78]$} \\
\hline & Temporal & Reduced power in left hemisphere & {$[80$} \\
\hline & Temporal & Enhanced power in left compared with right hemisphere & [74] \\
\hline & Parietal & Enhanced power in left compared with right hemisphere & [74] \\
\hline & Right posterior & Enhanced power in right hemisphere & [77] \\
\hline & Posterior-temporal & Enhanced power in left compared with right hemisphere & {$[72]$} \\
\hline & Central & Enhanced power in left compared with right hemisphere & {$[72,74]$} \\
\hline & Occipital & Enhanced power in left compared with right hemisphere & {$[72,74]$} \\
\hline & Occipital & No difference between left and right hemispheres & [105] \\
\hline \multirow[t]{9}{*}{ Alpha } & Frontal & Reduced power in left hemisphere & [80] \\
\hline & Mid-frontal & Enhanced power in left compared with right hemisphere & {$[106,107]$} \\
\hline & Temporal & Reduced power in left hemisphere & [80] \\
\hline & Temporal & Enhanced power in left compared with right hemisphere & [74] \\
\hline & Parietal & Enhanced power in left compared with right hemisphere & [74] \\
\hline & Posterior-temporal & Enhanced power in left compared with right hemisphere & [72] \\
\hline & Central & Enhanced power in left compared with right hemisphere & [72] \\
\hline & Occipital & Enhanced power in left compared with right hemisphere & [72] \\
\hline & Occipital & No difference between left and right hemispheres & [105] \\
\hline \multirow[t]{4}{*}{ Beta } & Posterior-temporal & Enhanced power in left compared with right hemisphere & [72] \\
\hline & Central & Enhanced power in left compared with right hemisphere & [72] \\
\hline & Occipital & Enhanced power in left compared with right hemisphere & {$[72]$} \\
\hline & Occipital & No difference between left and right hemispheres & [105] \\
\hline $\mathrm{Mu}$ & Central & No difference between left and right hemispheres & [74] \\
\hline
\end{tabular}

interaction between GABAergic interneurons and $\mathrm{N}$ methyl-D-aspartate receptors on glutamatergic neurons, which are in turn modulated by dopaminergic neurons in the thalamus [85]. ASD power abnormalities may result from a complex pattern of neurochemical alterations that affect the physiology of inhibitory GABAergic inter- neurons and their modulation of excitatory activity in pyramidal cells.

There is evidence that GABAergic interneuron development and connectivity is disrupted in the prefrontal and temporal cortices in ASD [86], and that this disruption is relevant to excitatory/inhibitory balance [87]. The GABA 


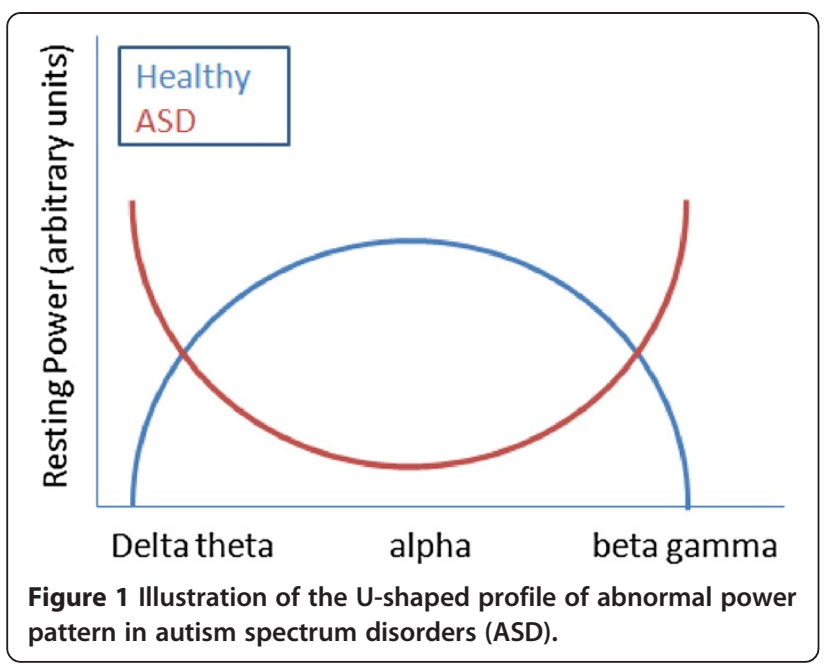

agonist lorazepam has been shown to increase long-range cortical functional connectivity in the alpha and low beta ranges [88], suggesting an association between GABA tone and large scale cortico-cortical connectivity. The middle alpha frequencies have commonly been associated with an 'idling' state, or more recently with active inhibition $[39,89]$, a state that has been associated with GABAergic circuitry [90]. GABAergic abnormalities can also have early developmental consequences, as GABA acts as an excitatory trophic factor prenatally, guiding growth and connectivity of dendrites [91]. Abnormal embryonic GABA concentrations could lead to development of abnormal excitatory/inhibitory circuitry, causing long-term alterations in the entire oscillatory activity at multiple frequencies. GABA abnormalities could bias neural networks away from the state of active inhibition (alpha) and towards greater excitation (higher frequencies). Intermittent thetaburst stimulation has been shown to increase cortical inhibition in rat neocortex by reducing parvalbumin expression in fast-spiking interneurons [92]. Stimulation in both the delta and theta frequency bands also increases expression of GABA precursors in inhibitory cortical systems [93]. In such cases, increased low-frequency activity could be a compensatory mechanism in ASD to halt the proliferation of high-frequency excitatory activation produced by GABAergic dysfunction. This hypothesis is also consistent with several studies that have documented GABAergic abnormalities in individuals with ASD [94]. Fatemi et al. $[95,96]$ showed reductions in GABA receptor density in cerebellum and Brodmann's areas 9 and 40 $[95,96]$. At the genetic level, it has been suggested that an interaction between GABA receptor subunit genes (GABRA4 and GABRB1) could be directly involved in the etiology of ASD by contributing to increased neuronal excitability, particularly during development, when GAB RA4 mRNA levels in brain tissues are at their highest [94]. Increased excitation/inhibition ratios reflecting
glutamatergic/GABAergic balance [97], induced by endogenously suppressed GABAergic inhibition [98-101], has been shown in some individuals with ASD. Alpha band power is thought to play an important role in top-down control of sensorimotor responses, including successful voluntary inhibition of contextually inappropriate responses [39]. Many children with ASD show increased levels of inattention and impulsivity [102,103], which may be linked to increased rates of inhibitory control errors in affected individuals [104]. Although associations between alpha power and inhibitory control deficits in ASD have not been directly examined, the potential role of this neurophysiological mechanism in this domain of behavioral impairment merits investigation.

There arre inconsistencies between studies regarding the U-shaped pattern of power in ASD. Reduced frontal low-frequency delta has been reported in children with ASD without ID [77] and reduced delta has been seen in the frontal and temporal regions in children with high-functioning and low-functioning ASD [80]. A few studies reported no differences in alpha frequency bands in children with ASD $[77,105]$ and enhanced alpha power over frontal/parietal/midline regions in high-functioning individuals with ASD [106]. Dawson and colleagues [80] found reduced theta band activity in the frontal, temporal, and parietal regions, with no effect in the beta band. Differences in participant characteristics such as IQ and age might account for the inconsistencies in these findings. Within the delta band, all enhanced delta findings (supporting the U-shaped curve hypothesis) have been most robust in relatively low-functioning children (mean IQ $=37$. [72]), those with over $20 \%$ mental age delay [74], and those with $28 \%$ lower intelligence score in ASD [73]. However, reduced delta power was reported in high-functioning children with ASD (mean Full Scale Intelligence Quotient of 93) by Coben et al. [77]. Findings of reduced alpha power (again supporting the U-shaped curve hypothesis) have been most consistent in lowfunctioning children with ASD $[72,73,80]$, but there are examples of this pattern in relatively high-functioning adults with ASD [76]. Studies reporting enhanced or unaffected alpha power were reported for high-functioning children with ASD $[77,105,106]$. The relation between resting EEG abnormalities and level of intellectual disability, impairments in various behavioral domains, history of regression, and other clinical features of ASD will be an important focus of future research in this area as larger, well-characterized cohorts are studied.

\section{Abnormal hemispheric asymmetry}

In addition to spectral power differences in individuals with ASD, changes have been reported in the hemispheric asymmetry of brain neurophysiology. The majority of the existing resting-state EEG literature reports enhanced 
power in the left compared with the right hemisphere in individuals with ASD, across all frequency bands $[72,74,78,106,107]$. This asymmetry is generally much larger than the mild individually variable asymmetries seen in typically developing humans [106].

Cantor and colleagues [72] reported that subjects with ASD had enhanced power in the delta band, in the posterior-temporal, midline, and occipital regions of the left hemisphere. Similarly, Stroganova et al. [74] found enhanced delta power in the left hemisphere of individuals with ASD in the frontal, temporal, and parietal regions. In the theta band, left-hemisphere dominance in ASD was seen in frontal [74,78], parietal [74], temporal [72,74], and occipital $[72,74]$ regions. In the alpha band, lefthemisphere dominance in ASD was reported in multiple studies in mid-frontal [106,107], temporal, parietal [72,74], midline [72,106], and occipital [72] regions. Finally, Cantor et al. [72] replicated the left-hemisphere dominance pattern in the beta band in posterior-temporal, midline, and occipital regions.

Left-hemisphere asymmetry in ASD is of clinical interest, given the common language abnormalities seen in ASD [108-111]. Increased resting power in the left hemisphere may contribute to left-hemisphere performance deficits by decreasing the signal-to-noise ratio during active tasks, similar to reports of increased background noise and behavioral performance impairment in the literature on schizophrenia [112,113]. Left-hemisphere dysfunction may also be dependent on the task that subjects are performing. When performing tasks of executive functioning (for example, Go/No-go and Stroop tests), high-functioning adults with ASD had significantly increased activation restricted to the left hemisphere [114]. Left-hemisphere dysfunction has also been identified in smooth pursuit eye movements in individuals with ASD [115], as have left-lateralized alterations during an oculomotor serial reaction time task [116].

Nevertheless, as in many neuropsychiatric disorders, evidence of lateralized abnormalities has been inconsistent [74]. Dawson et al. [80] reported reduced delta power in the left mid-temporal cortex, and Lazarev et al. [105] reported no left/right-hemisphere differences frequency bands in the occipital cortex. However, in the same and subsequent reports, the same authors noted hyperconnectivity within the left hemisphere [117] and reduced power in the right hemisphere [105] in children with ASD during presentation of photic driving stimulation. Dawson and colleagues [80] utilized a relatively short (1 second) window to measure delta power, which may affect reliability of measured low-frequency activity. Lazarev and colleagues [105,117] measured activity only in 14 relatively heterogeneous subjects with ASD, so those studies may have lacked statistical power to detect effects. Photic driving is a robust response, and would potentially be more sensitive to small pathological alterations in studies with small patient cohorts.

\section{Abnormal coherence}

Resting-state EEG studies of ASD have also documented reduced long-range coherence patterns [76,77,118,119]. Weaker coherence between frontal and occipital regions was reported for delta $[77,118]$ and theta [77] bands, whereas Murias and colleagues [76] reported significantly reduced alpha coherence between the frontal cortex and the temporal, parietal, and occipital cortices. Duffy and Als [119] reported weaker left frontal-temporal connectivity within the beta band. This finding is similar to results from multiple fMRI studies that have shown reduced left frontotemporal connectivity during resting state $[18,46,120]$. These findings parallel those from Horwitz and colleagues [121], who used positron emission tomography to show reduced correlations in glucose metabolism between frontal and other cortical areas in resting adults with ASD. Generalized decreases in frontoparietal and fronto-occipital connectivity have also been reported in ASD during resting fMRI [22,50]. These findings converge to suggest weakened long-range connectivity between the frontal lobe and other cortical regions. The frontal lobe plays a crucial role in higher-order cognitive, language, social, and emotional functioning [122]. Thus, it is not surprising that clear deficits in frontal lobe connectivity have been reported in ASD, as frontal lobe abnormalities have been proposed to play a key role in regulating a wide range of cognitive, sensory, and motor processes [123-125].

Findings on short-range connection patterns in resting EEG studies are less consistent. Both intrahemispheric and interhemispheric local coherences in all brain regions have been reported to be reduced in delta and theta bands [77], while a reduced local coherence over mid-frontal regions has been found in both the delta [118] and alpha band [76]. By contrast, enhanced local coherence has been found over the lateral-frontal region in the delta band [118], and over left frontal and temporal regions in the theta band [76]. Furthermore, these functional frontal deficits have been linked to structural abnormalities in the frontal lobe in ASD [126]. Although several studies have suggested excessive short-range connectivity in ASD, due to increased density of cortical mini-columns [123] and disproportionately increased white matter $[127,128]$, some diffusion tensor imaging (DTI) studies failed to report this pattern [49]. Although shortrange coherence studies will require more investigation with newer high-resolution DTI techniques, in parallel with resting-state measures of frontal connectivity using EEG, weaker long-range coherence between frontal and other brain regions found in resting EEG studies suggests that the frontal lobe is less well integrated with other local 
cortical areas, in ways likely to have considerable neurobehavioral significance [123]. Further examination of this model is necessary to understand how these functional abnormalities relate to clinical phenotypes.

\section{Crucial considerations}

Although previous studies of resting-state EEG in ASD have identified abnormalities in low-frequency and highfrequency band power, connectivity, and lateralization of brain functions, there are multiple crucial methodological and clinical issues that warrant attention in reviewing this literature and in planning future research.

\section{Small sample size with narrow range of subject characteristics} Many previous studies were conducted with small sample sizes (often with $<20$ subjects per group), as well as with subjects displaying a narrow range of demographic/clinical characteristics including age, intellectual ability, history of seizures, and severity of behavioral problems. Developmental variations in power at different frequencies, coherence, and lateralization of function are important considerations when studying a developmental disorder such as ASD, in which behavioral and cognitive presentations are diverse and can change over the age span $[129,130]$. Additionally, individuals with ASD vary widely in the extent to which their intellectual abilities are affected. IQ and educational levels were not consistent between previous studies of resting-state EEG, and at times, not even between patient and control groups. Other clinical aspects could also affect profiles of neurophysiological alterations in ASD, including comorbid medical and psychiatric conditions.

Many investigators did not conduct correlational analyses to relate abnormal EEG patterns to severity of various clinical aspects of ASD. This limits understanding of the clinical relevance of EEG observations. Of those studies reporting clinical correlations, Orekhova et al. [79] found a positive correlation between gamma activity and cognitive delay in ASD. Sutton et al. [106] reported that abnormal left frontal asymmetry, defined by greater activation in the left frontal regions, was related to higher levels of social anxiety and social stress, as was abnormal right frontal asymmetry. Stroganova et al. [74] showed that increased prefrontal delta power was related to cognitive delay in ASD. Burnett et al. [107] reported an association of left frontal EEG asymmetry with parental reports of later onset of ASD symptoms, and increased instances of aggressive outbursts and obsessive compulsive behavior. Finally, Barttfeld et al. [118] described a positive correlation between short-distance synchronization and Autism Diagnostic Observation Schedule (ADOS) scores [131], with a negative correlation between long-distance synchronization and ADOS scores, suggesting that there may be a clinically relevant excess of short-range func-tional connectivity coupled with a reduction in long-distance connectivity across the brain in ASD.

In future studies, it will be of great value to utilize large samples with a wide range of subject characteristics to increase the range of brain alterations and to better establish clinicopathological associations.

\section{Resting-state conditions}

Although the literature reviewed above referred to testing of subjects in the resting state, different studies have used eyes-closed (EC) and eyes-open (EO) conditions. In the EO condition, subjects typically viewed calming stimuli such as bubbles moving across a screen. Distinct EEG patterns in these two conditions were recently reported. Barry et al. [132] reported significant amplitude reductions in delta (lateral-frontal), theta (posterior), alpha (posterior), and beta (posterior) frequency bands in EO conditions relative to EC conditions. By contrast, increased frontal beta was found in EC conditions. Furthermore, skin conductance levels were higher in EO conditions, and were negatively correlated with alpha power, indicating a higher level of arousal. Chen et al. [133] reported enhanced prefrontal delta and reduced frontal-midline theta in EO states. Finally, reduced low alpha and low beta (13 to $23 \mathrm{~Hz})$ in the posterior region was reported during the EO condition, whereas high beta $(24$ to $34 \mathrm{~Hz}$ ) and gamma failed to show any difference between conditions. In evaluating the use of EO versus EC conditions in ASD, a recent study by Mathewson et al. [134] reported that adults with ASD did not differ from healthy controls on alpha power levels in the EC condition but displayed less alpha suppression during the EO condition. Although Barry and colleagues later replicated their resting EEG results for healthy adults [132] and children [135], a direct comparison of resting-state conditions has not been done in children with ASD, to our knowledge, so it is unclear whether a similar pattern would be seen in this population.

\section{EEG analysis methods: confounds and suggestions}

EEG studies need to be concerned about blurring sources of neural activity on EEG scalp recordings, due to the highly conductive nature of the scalp and differences in electrical conductivities between the brain, cerebrospinal fluid, and skull. Inhomogeneities in conductivity between tissues can change patterns of volume conduction (transmission of the electrical signal from the source to the measurement electrode), particularly when source models are calculated based on standard assumptions of tissue thickness and position, rather than the more realistic but not always available individual structural MRI measurements. These blurred recordings make it difficult to identify the source of atypical spectral activity, especially when fewer electrode leads are used in studies. 
Although the most consistent pattern of findings in the ASD literature is a U-shaped pattern of spectral power relative to healthy controls, the reported topographical locations of frequency band alterations in ASD have been disparate. For instance, in the delta band, significant power difference was presented in frontal [74,75], midline/parietal [73], temporal [80] or even all regions [72]. These widespread differences in topography could be due to widely distributed deficits within each frequency band, or due to data blurring, an issue that could be improved by comparing source densities between groups. In fact, in a source localization study on EEG oscillations [136], focal sources were reported for different frequency bands (for example, the most anterior source for delta and the most posterior source for alpha). However, resting frequency bands often show a distributed source network during simultaneous EEG-fMRI $[137,138]$, so the possibility that multiple sources within each frequency band may be contributing to differential findings between studies needs to be considered.

In addition to its effect on power, data blurring also has a large effect on coherence analysis, especially for short-range coherence. This could contribute to the mixed results for short-range coherence patterns that exist between resting-state EEG studies. Two techniques may help to resolve this blurring problem. One technique includes the use of surface Laplacian transformation to estimate current source density (CSD) based on EEG potentials, from which power and coherence can then be evaluated. CSD transformation computes the second spatial derivative of voltage between nearby electrode sites. This approach can enhance contributions from local electrical activity while attenuating contributions from remote activity (although care should be taken interpreting results if deep sources are of interest, as this technique is necessarily biased toward superficial cortical tissue). A recent resting EEG study with a large sample size utilized this technique to overcome the spatial blurring limitation, and found an overall reduction in short-range connectivity in ASD [119]. The second technique was proposed by Hoechstetter and colleagues [139], and in this technique, surface potentials are first transferred to source space by using multiple discrete equivalent current dipoles or regional sources. Coherence analysis is then calculated between source regions instead of electrodes. Cornew and colleagues [140] applied this technique in a resting-state magnetoencephalography study in high-functioning children with ASD, although they then quantified local oscillatory activity rather than coherence between regions.

The method of calculation of coherence itself is another important issue. As indicated by Murias et al. [76], coherence measured in short distances can be biased by power due to the classic coherence calculation frequently used in resting-state EEG studies. This calculation is a product of complex power spectrum decomposition, and it is sensitive to both amplitude and phase relationships between two signals. Strong power modulation at single sources can be detected by multiple nearby electrodes, inflating local connectivity measurements between these electrodes without reflecting the true coherence between separate but adjacent neural sources [141]. This induces the confounding factor of local source strength, limiting the certainty of the real cause of the relationship when concurrent power modulations are detected (although phase relationship usually has a larger contribution than amplitude [60]). To overcome this limitation, phase synchrony analysis methods represent an approach to assess the phase relationship independently. Lachaux and colleagues [142] proposed calculating a 'phase-locking value' (PLV) to measure phase synchrony. In their method, two EEG signals were first narrow band-passed (target frequency $\pm 2 \mathrm{~Hz}$ ), then convolved with the Gabor wavelet function. Finally, the phase outputs from wavelet decomposition between two signals were compared. PLV is a metric bound between 0 and 1 , with 1 indicating that phase difference varies little between trials (ERP) or segments (resting EEG), and 0 indicating a complete lack of phase synchrony. In addition to measuring phase relationships independently, another important feature is that PLV does not rest on the assumption of stationarity (between trials or segments) as in classic coherence calculation. Stationarity refers to the similarity of spectral properties between measurements, which can be more easily assumed with multiple trials that have identical stimulation periods, as in ERP tasks. In resting EEG, there are no clear breakpoints between segments of continuous data, and segment lengths are often based on the best tradeoff between frequency and temporal resolution, that is, how short each measurement segment can be while still affording accurate coverage of a number of oscillations in the frequency bands of interest. In the case of traditional coherence, non-stationarity of the power in a frequency band across time with no change in phase may present as changes in coherence values. Taking the confound between power and coherence into account is particularly important in studies of ASD, given reports of differences in resting-state spectral power in this population.

EEG recordings acquired in resting-state paradigms include both neural activity and non-neuronal activity such as muscular and cardiac activity, and ocular artifacts (for example, eye movement and eye blink). The conventional visual inspection and epoch rejection used in reviewed resting-state EEG studies may not be sufficient to completely remove these and other artifacts $[143,144]$. In this scenario, alternative solutions such as independent component analysis (ICA) [53] can serve as a complementary method. ICA is a linear decomposition method that 
separates a multivariate EEG signal into temporally independent signals available in the raw EEG channel data [145]. Each separate component can be treated like a virtual channel. Within each channel, noise components can be identified through component properties such as topography and spectral characteristics. The application of ICA to remove artifacts has been used with other clinical populations $[28,29,146]$, and can generate relatively artifact-free resting EEG data [119].

Finally, statistical methods such as principal components analysis have proven to be a useful method to distill multidimensional and complex EEG data into more manageable representative components of neural activity patterns $[147,148]$. This technique has been used to great advantage in coherence modeling in recent investigations of resting EEG in ASD [119].

\section{Future directions}

\section{The maturational trajectory of resting-state activity in ASD}

Few studies have compared individuals with ASD and healthy individuals, either cross-sectionally between age groups, or longitudinally. A recent longitudinal study of infants at high and low risk for ASD reported changes in developmental trajectory, that is, the slope of the power curve across time, related to risk status from 6 to 24 months of age, particularly in the delta, beta, and gamma frequency ranges [81]. This same group also reported changes in the developmental trajectory of overall EEG complexity (entropy) for high-risk infants as compared with typically developing controls across the same time window [149]. One 3-month longitudinal study in children with ASD indicated that EEG characteristics are relatively stable across short time intervals [150]. Longer-term longitudinal studies are needed to understand whether individuals with ASD show similar trajectories of functional connectivity maturation, or whether these processes are disrupted and/ or delayed. Behavioral longitudinal studies of children with ASD indicate an early improvement in language and cognitive skills in some affected individuals (ages 12 to 13 years) followed by considerable and abnormal decrease in the rate of gains through adolescence (ages 19 to 20 years) [151]. These findings raise the possibility that developmental lag or deviance becomes more profound during late childhood and adolescence as the longrange connections to prefrontal cortex are optimized [152]. Reports of resting-state EEG data in younger ASD cohorts are beginning to appear, but studies on a long-term and/or adolescent sample would provide potentially important information about functional connectivity changes accompanying ASD through childhood and adolescence.

\section{Early detection and possible biomarkers for ASD}

Retrospective studies of infants later diagnosed with ASD have shown that features of ASD are present as early as
12 months. However, many children are not diagnosed until the age of 4 years or later $[153,154]$. This highlights the need for biomarkers for early detection in order to implement early intervention [155]. It is difficult to reliably identify individuals with ASD within the first year of life based only on behavioral observation, but studies of resting-state EEG suggest that selective alterations may be identifiable as early as 6 months $[81,149]$. Globally reduced power of delta, theta, alpha, beta and gamma frequency bands have been found in high-risk infants with siblings with ASD compared with low-risk 6-month-old control infants [81]. However, no group difference in hemispheric asymmetry was reported. Elsabbagh et al. [156] reported increased gamma band activity in the midline anterior and right temporal cortex of high-risk infants. Currently, there are few studies to determine the utility of these measures in at risk children for identifying individuals with a high likelihood of developing ASD later in life.

\section{Resting-state EEG studies in ASD with genetic etiology}

The heterogeneous nature of idiopathic ASD can make studies of the underlying etiology difficult. However, a small subset of individuals with ASD (10 to 20\%) is believed to have 'simpler' genetics, possessing identifiable chromosomal abnormalities or rare mutations found in higher ratios in the ASD population. High proportions of individuals with Fragile $\mathrm{X}$ syndrome, Rett syndrome [157], tuberous sclerosis [158], and Phelan-McDermid syndrome [159] have ASD, and each of these disorders has been linked to known abnormalities of individual genes (for example, FMRI1, MECP2, TSC1, TSC2). Further, several rare de novo mutations, some of which converge on pathways that overlap with those associated with Fragile $\mathrm{X}$ and tuberous sclerosis, and are linked to synapse formation and function, have been found to be more common in this population [5]. Using resting-state EEG, it may be possible to connect distinct patterns of altered electrophysiological activity with symptoms found in identified single-gene disorders related to ASD. To date, few studies have utilized ERP in subjects with Fragile X syndrome [160] and primarily epileptiform activity has been examined in resting-state EEG in this population $[132,161]$; however, there is some evidence for increased resting theta activity in Fragile X [162-164]. The use of EEG to examine Rett syndrome has followed a similar path, with the majority of resting EEG studies dedicated to describing seizure activity (but see studies by Ishizaki [165] and Niedermeyer et al. [166] for evidence of prominent resting theta activity in Rett syndrome). Currently, there are no published accounts of resting EEG in Phelan-McDermid syndrome, although changes in excitatory/inhibitory balance in the brains of knockout mouse models suggest measurable electrophysiological 
changes in this disorder [167]. It would be of particular interest to study resting EEG in these known single-gene conditions, particularly Fragile X, one of the better characterized single-gene disorders, potentially serving as reference for other subpopulations in ASD and shedding light on biological mechanisms shared across the autism spectrum. Whether resting EEG studies can be useful for parsing biological heterogeneity of idiopathic ASD remains another important question to be addressed in future studies.

\section{Conclusions}

In this review, we have addressed resting-state EEG studies in ASD with an emphasis on three aspects: spectral power, coherence, and hemispheric asymmetry. The existing literature suggests a U-shaped pattern of power abnormalities, overall local overconnectivity and longrange underconnectivity, and enhanced power in the left hemisphere of the brain in individuals with ASD. There are important considerations for EEG methodology and clinical assessment that both need consideration for designing the most informative future studies. Recent advances in quantitative EEG analytic methodology and scientific findings from work in this area are encouraging. Future work linking EEG studies of animal models with patient-oriented studies are promising, especially for rare genetic variants for which animal models are most directly relevant. Because of a combination of advantages including its non-invasive nature, high temporal resolution, and relative ease of use across the lifespan, resting-state EEG studies have the potential to make important contributions to the understanding of the pathophysiology of ASD.

\section{Competing interests}

JS serves as a member of advisory boards to Takeda, Lilly, BMS, Roche and Pfizer, and has received support from Janssen that is unrelated to the work presented in this manuscript.

\section{Authors' contributions}

$J W, J B, M W$ and JS made substantial contributions to design of this study. $J W$ and JB wrote the first draft of the manuscript, and LE, MW, YT and JS revised the manuscript. All authors contributed to writing the manuscript. All authors read and approved the final manuscript.

\section{Acknowledgement \\ Funding \\ This study was funded by the NIMH Autism Center of Excellence 1P5OHD055751-01, K23MH092696, K01MH087720, Department of the Army award AR100276, and Autism Speaks.}

\section{Author details}

'Department of Psychiatry, University of Texas Southwestern, Dallas, TX, USA. ${ }^{2}$ Department of Pediatrics, University of Texas Southwestern, Dallas, TX, USA. ${ }^{3}$ Center for Autism Spectrum Disorders, Bond University, Gold Coast, Australia.

Received: 13 May 2013 Accepted: 4 September 2013 Published: 16 September 2013

\section{References}

1. American Psychiatric Association: Diagnostic and statistical manual of mental disorders-4th edition; 2000.

2. Centers for Disease Control and Prevention: Prevalence of autism spectrum disorders--Autism and Developmental Disabilities Monitoring Network, 14 sites; 2012

3. Muhle R, Trentacoste SV, Rapin I: The genetics of autism. Pediatrics 2004, 113:e472-e486.

4. Ozonoff S, Young GS, Carter A, Messinger D, Yirmiya N, Zwaigenbaum L, Bryson S, Carver LJ, Constantino JN, Dobkins K, et al: Recurrence risk for autism spectrum disorders: a baby siblings research consortium study. Pediatrics 2011, 128:e488-e495.

5. Abrahams BS, Geschwind DH: Advances in autism genetics: on the threshold of a new neurobiology. Nat Rev Genet 2008, 9:341-355.

6. Chakrabarti S, Fombonne E: Pervasive developmental disorders in preschool children: confirmation of high prevalence. Am J Psychiatry 2005, 162:1133-1141.

7. Parr JR, Le Couteur A, Baird G, Rutter M, Pickles A, Fombonne E, Bailey AJ: International molecular genetic study of autism consortium M: early developmental regression in autism spectrum disorder: evidence from an international multiplex sample. J Autism Dev Disord 2011, 41:332-340.

8. Akshoomoff N, Pierce K, Courchesne E: The neurobiological basis of autism from a developmental perspective. Dev Psychopathol 2002 14:613-634.

9. Takarae Y, Minshew NJ, Luna B, Sweeney JA: Atypical involvement of frontostriatal systems during sensorimotor control in autism. Psychiatry Res 2007, 156:117-127.

10. Bauman ML, Kemper TL: Neuroanatomic observations of the brain in autism: a review and future directions. Int J Dev Neurosci 2005, 23:183-187.

11. Courchesne E, Karns CM, Davis HR, Ziccardi R, Carper RA, Tigue ZD, Chisum HJ, Moses P, Pierce K, Lord C, et al: Unusual brain growth patterns in early life in patients with autistic disorder: an MRI study. Neurology 2001, 57:245-254.

12. Courchesne $E$, Pierce $K$ : Brain overgrowth in autism during a critical time in development: implications for frontal pyramidal neuron and interneuron development and connectivity. Int J Dev Neurosci 2005, 23:153-170.

13. Mosconi MW, Cody-Hazlett H, Poe MD, Gerig G, Gimpel-Smith R, Piven J: Longitudinal study of amygdala volume and joint attention in 2- to 4-year-old children with autism. Arch Gen Psychiatry 2009, 66:509-516

14. Aylward EH, Minshew NJ, Field K, Sparks BF, Singh N: Effects of age on brain volume and head circumference in autism. Neurology 2002, 59:175-183.

15. Redcay $E$, Courchesne $E$ : When is the brain enlarged in autism? a meta-analysis of all brain size reports. Biol Psychiatry 2005, 58:1-9.

16. Mosconi MW, Zwaigenbaum L, Piven J: Structural MRI in autism: findings and future directions. Clin Neurosci Res 2006, 6:135-144.

17. Knaus TA, Silver AM, Lindgren KA, Hadjikhani N, Tager-Flusberg H: fMRI activation during a language task in adolescents with ASD. JINS 2008, 14:967-979.

18. Koshino H, Kana RK, Keller TA, Cherkassky VL, Minshew NJ, Just MA: fMRI investigation of working memory for faces in autism: visual coding and underconnectivity with frontal areas. Cereb Cortex 2008, 18:289-300.

19. Schultz RT, Gauthier I, Klin A, Fulbright RK, Anderson AW, Volkmar F, Skudlarski P, Lacadie C, Cohen DJ, Gore JC: Abnormal ventral temporal cortical activity during face discrimination among individuals with autism and Asperger syndrome. Arch Gen Psychiatry 2000, 57:331-340.

20. Pierce K, Muller RA, Ambrose J, Allen G, Courchesne E: Face processing occurs outside the fusiform 'face area' in autism: evidence from functional MRI. Brain 2001, 124:2059-2073.

21. Muller RA, Pierce K, Ambrose JB, Allen G, Courchesne E: Atypical patterns of cerebral motor activation in autism: a functional magnetic resonance study. Biol Psychiatry 2001, 49:665-676.

22. Cherkassky VL, Kana RK, Keller TA, Just MA: Functional connectivity in a baseline resting-state network in autism. Neuroreport 2006, 17:1687-1690.

23. Kennedy DP, Courchesne E: The intrinsic functional organization of the brain is altered in autism. Neuroimage 2008, 39:1877-1885.

24. Kennedy DP, Redcay E, Courchesne E: Failing to deactivate: resting functional abnormalities in autism. Proc Natl Acad Sci U S A 2006, 103:8275-8280

25. Schumann CM, Bloss CS, Barnes CC, Wideman GM, Carper RA, Akshoomoff N, Pierce K, Hagler D, Schork N, Lord C, Courchesne E: Longitudinal 
magnetic resonance imaging study of cortical development through early childhood in autism. J Neurosci 2010, 30:4419-4427.

26. Regan D: Human Brain Electrophysiology: Evoked Potentials and Evoked Magnetic Fields in Science and Medicine. New York: McGraw-Hill; 1989.

27. Mann CA, Lubar JF, Zimmerman AW, Miller CA, Muenchen RA: Quantitative analysis of EEG in boys with attention-deficit-hyperactivity disorder: controlled study with clinical implications. Pediatr Neurol 1992, 8:30-36.

28. Wang J, Brown R, Dobkins KR, McDowell JE, Clementz BA: Diminished parietal cortex activity associated with poor motion direction discrimination performance in schizophrenia. Cereb Cortex 2010, 20:1749-1755.

29. Ethridge LE, Hamm JP, Shapiro JR, Summerfelt AT, Keedy SK, Stevens MC, Pearlson G, Tamminga CA, Boutros NN, Sweeney JA, et al: Neural activations during auditory oddball processing discriminating schizophrenia and psychotic bipolar disorder. Biol Psychiatry 2012, 72:766-774.

30. Coben R: The importance of electroencephalogram assessment for autistic disorders. Biofeedback 2009, 37:71-80.

31. Tuchman R, Rapin I: Epilepsy in autism. Lancet Neurol 2002, 1:352-358.

32. Tuchman RF, Rapin I: Regression in pervasive developmental disorders: seizures and epileptiform electroencephalogram correlates. Pediatrics 1997, 99:560-566.

33. Rossi PG, Parmeggiani A, Bach V, Santucci M, Visconti P: EEG features and epilepsy in patients with autism. Brain Dev 1995, 17:169-174.

34. Hughes JR, Melyn M: EEG and seizures in autistic children and adolescents: further findings with therapeutic implications. Clinical EEG Neuroscience 2005, 36:15-20.

35. Chez MG, Chang M, Krasne V, Coughlan C, Kominsky M, Schwartz A: Frequency of epileptiform EEG abnormalities in a sequential screening of autistic patients with no known clinical epilepsy from 1996 to 2005. Epilepsy Behav 2006, 8:267-271.

36. Basar E, Basar-Eroglu C, Karakas S, Schurmann M: Gamma, alpha, delta, and theta oscillations govern cognitive processes. Int J Psychophysiol 2001, 39:241-248.

37. Knyazev GG: EEG delta oscillations as a correlate of basic homeostatic and motivational processes. Neurosci Biobehav Rev 2012, 36:677-695.

38. Klimesch W: Memory processes, brain oscillations and EEG synchronization. Int J Psychophysiol 1996, 24:61-100.

39. Klimesch W, Sauseng P, HansImayr S: EEG alpha oscillations: the inhibition-timing hypothesis. Brain Res Rev 2007, 53:63-88.

40. Neuper C, Pfurtscheller G: Event-related dynamics of cortical rhythms: frequency-specific features and functional correlates. Int J Psychophysiol 2001, 43:41-58.

41. Tallon-Baudry C: Oscillatory synchrony and human visual cognition. J Physiol Paris 2003, 97:355-363.

42. Skinner JE, Molnar M, Kowalik ZJ: The role of the thalamic reticular neurons in alpha- and gamma-oscillations in neocortex: a mechanism for selective perception and stimulus binding. Acta Neurobiol Exp 2000, 60:123-142.

43. Singer $W$, Gray CM: Visual feature integration and the temporal correlation hypothesis. Annu Rev Neurosci 1995, 18:555-586.

44. Olejniczak P: Neurophysiologic basis of EEG. J Clin Neurophysiol 2006, 23:186-189.

45. Barnea-Goraly N, Kwon H, Menon V, Eliez S, Lotspeich L, Reiss AL: White matter structure in autism: preliminary evidence from diffusion tensor imaging. Biol Psychiatry 2004, 55:323-326.

46. Just MA, Cherkassky VL, Keller TA, Minshew NJ: Cortical activation and synchronization during sentence comprehension in high-functioning autism: evidence of underconnectivity. Brain 2004, 127:1811-1821.

47. Herbert MR, Ziegler DA, Deutsch CK, O'Brien LM, Kennedy DN, Filipek PA, Bakardjiev Al, Hodgson J, Takeoka M, Makris N, Caviness VS Jr: Brain asymmetries in autism and developmental language disorder: a nested whole-brain analysis. Brain 2005, 128:213-226.

48. Alexander AL, Lee JE, Lazar M, Boudos R, DuBray MB, Oakes TR, Miller JN, Lu J, Jeong EK, McMahon WM, et al: Diffusion tensor imaging of the corpus callosum in Autism. Neuroimage 2007, 34:61-73.

49. Sundaram SK, Kumar A, Makki MI, Behen ME, Chugani HT, Chugani DC: Diffusion tensor imaging of frontal lobe in autism spectrum disorder. Cerebral cortex 2008, 18:2659-2665.

50. Monk CS, Peltier SJ, Wiggins JL, Weng SJ, Carrasco M, Risi S, Lord C: Abnormalities of intrinsic functional connectivity in autism spectrum disorders. Neuroimage 2009, 47:764-772.
51. Wass S: Distortions and disconnections: disrupted brain connectivity in autism. Brain Cogn 2011, 75:18-28.

52. Fox MD, Greicius M: Clinical applications of resting state functional connectivity. Front Syst Neurosci 2010, 4:19.

53. Makeig S, Delorme A, Westerfield M, Jung TP, Townsend J, Courchesne E, Sejnowski TJ: Electroencephalographic brain dynamics following manually responded visual targets. PLOS Biol 2004, 2:e176.

54. Fox MD, Snyder AZ, Zacks JM, Raichle ME: Coherent spontaneous activity accounts for trial-to-trial variability in human evoked brain responses. Nat Neurosci 2006, 9:23-25.

55. Fox MD, Raichle ME: Spontaneous fluctuations in brain activity observed with functional magnetic resonance imaging. Nat Rev Neurosci 2007, 8:700-711

56. Olshausen BA, Field DJ: How close are we to understanding v1? Neural Comput 2005, 17:1665-1699.

57. Raichle ME, Snyder AZ: A default mode of brain function: a brief history of an evolving idea. Neuroimage 2007, 37:1083-1090. discussion 1097-1089.

58. Gruber WR, Klimesch W, Sauseng P, Doppelmayr M: Alpha phase synchronization predicts $\mathrm{P} 1$ and $\mathrm{N} 1$ latency and amplitude size. Cereb Cortex 2005, 15:371-377.

59. Mazaheri A, Nieuwenhuis IL, van Dijk H, Jensen O: Prestimulus alpha and mu activity predicts failure to inhibit motor responses. Hum Brain Mapp 2009, 30:1791-1800.

60. Srinivasan R, Nunez PL, Silberstein RB: Spatial filtering and neocortical dynamics: estimates of EEG coherence. IEEE Trans Biomed Eng 1998, 45:814-826.

61. Whitford TJ, Rennie CJ, Grieve SM, Clark CR, Gordon E, Williams LM: Brain maturation in adolescence: concurrent changes in neuroanatomy and neurophysiology. Hum Brain Mapp 2007, 28:228-237.

62. Pineda JA, Brang D, Hecht E, Edwards L, Carey S, Bacon M, Futagaki C, Suk D, Tom J, Birnbaum C, Rork A: Positive behavioral and electrophysiological changes following neurofeedback training in children with autism. Res Autism Spectrum Disord 2008, 2:557-581.

63. Rimland B, Edelson M: Autism Treatment Evaluation Checklist (ATEC); 1999.

64. Kouiizer M, De Moor J, Gerrits B, Buitelaar JK, Van Schie H: Long-term effects of neurofeedback treatment in autism. Res Autism Spectrum Disord 2009, 3:496-501.

65. Kouijzer M, De Moor J, Gerrits B, Congedo M, Van Schie H: Research in Autism Spectrum Disorders. 3 Neurofeedback improves executive functioning in chidlren with autism spectrum disorders; 2009:145-162.

66. White PT, Demyer W, Demyer M: Eeg abnormalities in early childhood schizophrenia: a double-blind study of psychiatrically disturbed and normal children during promazine sedation. Am J Psychiatry 1964, 120:950-958.

67. Hutt SJ, Hutt C, Lee D, Ounsted C: A behavioural and electroencephalographic study of autistic children. J Psychiatr Res 1965, 3:181-197.

68. Hermelin $\mathrm{B}, \mathrm{O}^{\prime}$ Connor $\mathrm{N}$ : Measures of the occipital alpha rhythm in normal, subnormal and autistic children. Br J Psychiatry 1968, 114:603-610.

69. Creak M, Pampiglione G: Clinical and EEG studies on a group of 35 psychotic children. Dev Med Child Neurol 1969, 11:218-227.

70. Small JG: EEG and neurophysiological studies of early infantile autism. Biol Psychiatry 1975, 10:385-397.

71. Pivik RT, Broughton RJ, Coppola R, Davidson RJ, Fox N, Nuwer MR: Guidelines for the recording and quantitative analysis of electroencephalographic activity in research contexts. Psychophysiology 1993, 30:547-558.

72. Cantor DS, Thatcher RW, Hrybyk M, Kaye H: Computerized EEG analyses of autistic children. J Autism Dev Disord 1986, 16:169-187.

73. Chan AS, Sze SL, Cheung MC: Quantitative electroencephalographic profiles for children with autistic spectrum disorder. Neuropsychology 2007, 21:74-81.

74. Stroganova TA, Nygren G, Tsetlin MM, Posikera IN, Gillberg C, Elam M, Orekhova EV: Abnormal EEG lateralization in boys with autism. Clin Neurophysiol 2007, 118:1842-1854.

75. Pop-Jordanova N, Zorcec T, Demerdzieva A, Gucev Z: QEEG characteristics and spectrum weighted frequency for children diagnosed as autistic spectrum disorder. Nonlinear Biomedical Physics 2010, 4:4.

76. Murias M, Webb SJ, Greenson J, Dawson G: Resting state cortical connectivity reflected in EEG coherence in individuals with autism. Biol Psychiatry 2007, 62:270-273. 
77. Coben R, Clarke AR, Hudspeth W, Barry RJ: EEG power and coherence in autistic spectrum disorder. Clin Neurophysiol 2008, 119:1002-1009.

78. Daoust AM, Limoges E, Bolduc C, Mottron L, Godbout R: EEG spectral analysis of wakefulness and REM sleep in high functioning autistic spectrum disorders. Clin Neurophysiol 2004, 115:1368-1373.

79. Orekhova EV, Stroganova TA, Nygren G, Tsetlin MM, Posikera IN, Gillberg C, Elam M: Excess of high frequency electroencephalogram oscillations in boys with autism. Biol Psychiatry 2007, 62:1022-1029.

80. Dawson G, Klinger LG, Panagiotides H, Lewy A, Castelloe P: Subgroups of autistic children based on social behavior display distinct patterns of brain activity. J Abnorm Child Psychol 1995, 23:569-583.

81. Tierney AL, Gabard-Durnam L, Vogel-Farley V, Tager-Flusberg H, Nelson CA: Developmental trajectories of resting EEG power: an endophenotype of autism spectrum disorder. PloS one 2012, 7:e39127.

82. Wendling F, Bartolomei F, Bellanger JJ, Chauvel P: Epileptic fast activity can be explained by a model of impaired GABAergic dendritic inhibition. Eur J Neurosci 2002, 15:1499-1508.

83. Halonen T, Pitkanen A, Koivisto E, Partanen J, Riekkinen PJ: Effect of vigabatrin on the electroencephalogram in rats. Epilepsia 1992, 33:122-127.

84. Marciani MG, Stanzione P, Maschio M, Spanedda F, Bassetti MA, Mattia D, Bernardi G: EEG changes induced by vigabatrin monotherapy in focal epilepsy. Acta Neurol Scand 1997, 95:115-120.

85. Zhang Y, Llinas RR, Lisman JE: Inhibition of NMDARs in the nucleus reticularis of the thalamus produces delta frequency bursting. Frontiers in Neural Circuits 2009, 3:20.

86. Casanova MF, Buxhoeveden DP, Switala AE, Roy E: Minicolumnar pathology in autism. Neurology 2002, 58:428-432.

87. Levitt P: Disruption of interneuron development. Epilepsia 2005, 46(Suppl 7):22-28.

88. Fingelkurts AA, Kivisaari R, Pekkonen E, Ilmoniemi RJ, Kahkonen S: The interplay of lorazepam-induced brain oscillations: microstructural electromagnetic study. Clin Neurophysiol 2004, 115:674-690.

89. Mathewson KE, Lleras A, Beck DM, Fabiani M, Ro T, Gratton G: Pulsed out of awareness: EEG alpha oscillations represent a pulsed-inhibition of ongoing cortical processing. Front Psychol 2011, 2:99.

90. Jensen O, Mazaheri A: Shaping functional architecture by oscillatory alpha activity: gating by inhibition. Front Hum Neurosci 2010, 4:186.

91. Owens DF, Kriegstein AR: Is there more to GABA than synaptic inhibition? Nat Rev Neurosci 2002, 3:715-727.

92. Benali A, Trippe J, Weiler E, Mix A, Petrasch-Parwez E, Girzalsky W, Eysel UT, Erdmann R, Funke K: Theta-burst transcranial magnetic stimulation alters cortical inhibition. J Neurosci 2011, 31:1193-1203.

93. Trippe J, Mix A, Aydin-Abidin S, Funke K, Benali A: Theta burst and conventional low-frequency rTMS differentially affect GABAergic neurotransmission in the rat cortex. Experimental Brain Research Experimentelle Hirnforschung Experimentation cerebrale 2009, 199:411-421.

94. Ma DQ, Whitehead PL, Menold MM, Martin ER, Ashley-Koch AE, Mei H, Ritchie MD, Delong GR, Abramson RK, Wright HH, et al: Identification of significant association and gene-gene interaction of GABA receptor subunit genes in autism. Am J Hum Genet 2005, 77:377-388.

95. Fatemi SH, Reutiman TJ, Folsom TD, Thuras PD: GABA(A) receptor downregulation in brains of subjects with autism. J Autism Dev Disord 2009, 39:223-230.

96. Fatemi SH, Folsom TD, Reutiman TJ, Thuras PD: Expression of GABA(B) receptors is altered in brains of subjects with autism. Cerebellum 2009, 8:64-69.

97. Rubenstein $J$, Merzenich MM: Model of autism: increased ratio of excitation/inhibition in key neural systems. Genes Brain Behav 2003, 2:255-267.

98. Hussman JP: Suppressed GABAergic inhibition as a common factor in suspected etiologies of autism. J Autism Dev Disord 2001, 31:247-248.

99. Schmitz C, van Kooten IA, Hof PR, van Engeland H, Patterson PH, Steinbusch HW: Autism: neuropathology, alterations of the GABAergic system, and animal models. Int Rev Neurobiol 2005, 71:1-26.

100. Delong R: GABA(A) receptor alpha5 subunit as a candidate gene for autism and bipolar disorder: a proposed endophenotype with parent-oforigin and gain-of-function features, with or without oculocutaneous albinism. Autism 2007, 11:135-147.

101. Thatcher RW, North DM, Neubrander J, Biver CJ, Cutler S, Defina P: Autism and EEG phase reset: deficient GABA mediated inhibition in thalamo-cortical circuits. Dev Neuropsychol 2009, 34:780-800.
102. Goldstein S, Schwebach AJ: The comorbidity of pervasive developmental disorder and attention deficit hyperactivity disorder: results of a retrospective chart review. J Autism Dev Disord 2004, 34:329-339.

103. Yoshida $Y$, Uchiyama $T$ : The clinical necessity for assessing attention deficit/hyperactivity disorder (AD/HD) symptoms in children with high-functioning pervasive developmental disorder (PDD). Eur Child Adolesc Psychiatry 2004, 13:307-314.

104. Mosconi MW, Kay M, D'Cruz AM, Seidenfeld A, Guter S, Stanford LD, Sweeney JA: Impaired inhibitory control is associated with higher-order repetitive behaviors in autism spectrum disorders. Psychol Med 2009, 39:1559-1566.

105. Lazarev W, Pontes A, De Azevedo LC: EEG photic driving: right-hemisphere reactivity deficit in childhood autism. A pilot study. Int J Psychophysiol 2009, 71:177-183.

106. Sutton SK, Burnette CP, Mundy PC, Meyer J, Vaughan A, Sanders C, Yale M: Resting cortical brain activity and social behavior in higher functioning children with autism. J Child Psychol Psychiatry 2005, 46:211-222.

107. Burnette CP, Henderson HA, Inge AP, Zahka NE, Schwartz CB, Mundy PC: Anterior EEG asymmetry and the modifier model of autism. J Autism Dev Disord 2011, 41:1113-1124.

108. Dawson G, Finley C, Phillips S, Lewy A: A comparison of hemispheric asymmetries in speech-related brain potentials of autistic and dysphasic children. Brain Lang 1989, 37:26-41.

109. Herbert MR, Harris GJ, Adrien KT, Ziegler DA, Makris N, Kennedy DN, Lange NT, Chabris CF, Bakardjiev A, Hodgson J, et al: Abnormal asymmetry in language association cortex in autism. Ann Neurol 2002, 52:588-596.

110. Rojas DC, Bawn SD, Benkers TL, Reite ML, Rogers SJ: Smaller left hemisphere planum temporale in adults with autistic disorder. Neurosci Lett 2002, 328:237-240

111. De Fosse L, Hodge SM, Makris N, Kennedy DN, Caviness VS Jr, McGrath L, Steele S, Ziegler DA, Herbert MR, Frazier JA, et al: Language-association cortex asymmetry in autism and specific language impairment. Ann Neurol 2004, 56:757-766.

112. Winterer G, Ziller M, Dorn H, Frick K, Mulert C, Wuebben Y, Herrmann WM, Coppola R: Schizophrenia: reduced signal-to-noise ratio and impaired phase-locking during information processing. Clin Neurophysio/ 2000 111:837-849.

113. Winterer G, Weinberger DR: Genes, dopamine and cortical signal-to-noise ratio in schizophrenia. Trends Neurosci 2004, 27:683-690.

114. Schmitz N, Rubia K, Daly E, Smith A, Williams S, Murphy DG: Neural correlates of executive function in autistic spectrum disorders. Biol Psychiatry 2006, 59:7-16.

115. Takarae Y, Minshew NJ, Luna B, Krisky CM, Sweeney JA: Pursuit eye movement deficits in autism. Brain 2004, 127:2584-2594

116. D'Cruz AM, Mosconi MW, Steele S, Rubin LH, Luna B, Minshew N, Sweeney JA: Lateralized response timing deficits in autism. Biol Psychiatry 2009, 66:393-397

117. Lazarev W, Pontes A, Mitrofanov AA, De Azevedo LC: Interhemispheric asymmetry in EEG photic driving coherence in childhood autism. Clin Neurophysiol 2010, 121:145-152.

118. Barttfeld P, Wicker B, Cukier S, Navarta S, Lew S, Sigman M: A big-world network in ASD: dynamical connectivity analysis reflects a deficit in long-range connections and an excess of short-range connections. Neuropsychologia 2011, 49:254-263.

119. Duffy FH, Als H: A stable pattern of EEG spectral coherence distinguishes children with autism from neuro-typical controls - a large case control study. BMC Med 2012, 10:64

120. Sato W, Toichi M, Uono S, Kochiyama T: Impaired social brain network for processing dynamic facial expressions in autism spectrum disorders. BMC Neurosci 2012, 13:99

121. Horwitz B, Rumsey JM, Grady CL, Rapoport SI: The cerebral metabolic landscape in autism. Intercorrelations Reg Glucose Util Arch Neurol 1988, 45:749-755.

122. Stuss DT, Knight RT: Principles of Frontal Lobe Function. Oxford: Oxford University Press; 2002.

123. Courchesne $\mathrm{E}$, Pierce $\mathrm{K}$ : Why the frontal cortex in autism might be talking only to itself: local over-connectivity but long-distance disconnection. Curr Opin Neurobiol 2005, 15:225-230.

124. Geschwind DH, Levitt P: Autism spectrum disorders: developmental disconnection syndromes. Curr Opin Neurobiol 2007, 17:103-111. 
125. Shalom DB: The medial prefrontal cortex and integration in autism. Neuroscientist 2009, 15:589-598.

126. Carper RA, Moses P, Tigue ZD, Courchesne E: Cerebral lobes in autism: early hyperplasia and abnormal age effects. Neuroimage 2002, 16:1038-1051.

127. Herbert MR, Ziegler DA, Deutsch CK, O'Brien LM, Lange N, Bakardjiev A, Hodgson J, Adrien KT, Steele S, Makris N, et al: Dissociations of cerebral cortex, subcortical and cerebral white matter volumes in autistic boys. Brain 2003, 126:1182-1192.

128. Herbert MR, Ziegler DA, Makris N, Filipek PA, Kemper TL, Normandin JJ, Sanders HA, Kennedy DN, Caviness VS Jr: Localization of white matter volume increase in autism and developmental language disorder. Ann Neurol 2004, 55:530-540.

129. Anderson DK, Oti RS, Lord C, Welch K: Patterns of growth in adaptive social abilities among children with autism spectrum disorders. J Abnorm Child Psychol 2009, 37:1019-1034.

130. Seltzer MM, Shattuck P, Abbeduto L, Greenberg JS: Trajectory of development in adolescents and adults with autism. Ment Retard Dev Disabil Res Rev 2004, 10:234-247.

131. Lord C, Risi S, Lambrecht L, Cook EH Jr, Leventhal BL, DiLavore PC, Pickles A, Rutter M: The autism diagnostic observation schedule-generic: a standard measure of social and communication deficits associated with the spectrum of autism. J Autism Dev Disord 2000, 30:205-223.

132. Barry RJ, Clarke AR, Johnstone SJ, Magee CA, Rushby JA: EEG differences between eyes-closed and eyes-open resting conditions. Clin Neurophysiol 2007, 118:2765-2773.

133. Chen AC, Feng W, Zhao H, Yin Y, Wang P: EEG default mode network in the human brain: spectral regional field powers. Neuroimage 2008, 41:561-574.

134. Mathewson KJ, Jetha MK, Drmic IE, Bryson SE, Goldberg JO, Schmidt LA: Regional EEG alpha power, coherence, and behavioral symptomatology in autism spectrum disorder. Clin Neurophysiol 2012, 123:1798-1809.

135. Barry RJ, Clarke AR, Johnstone SJ, Brown CR: EEG differences in children between eyes-closed and eyes-open resting conditions. Clin Neurophysiol 2009, 120:1806-1811.

136. Michel CM, Lehmann D, Henggeler B, Brandeis D: Localization of the sources of EEG delta, theta, alpha and beta frequency bands using the FFT dipole approximation. Electroencephalogr Clin Neurophysiol 1992, 82:38-44.

137. Hlinka J, Alexakis C, Diukova A, Liddle PF, Auer DP: Slow EEG pattern predicts reduced intrinsic functional connectivity in the default mode network: an inter-subject analysis. Neuroimage 2010, 53:239-246.

138. Mo J, Liu Y, Huang H, Ding M: Coupling between visual alpha oscillations and default mode activity. Neuroimage 2013, 68:112-118.

139. Hoechstetter K, Bornfleth H, Weckesser D, Ille N, Berg P, Scherg M: BESA source coherence: a new method to study cortical oscillatory coupling. Brain Topogr 2004, 16:233-238.

140. Cornew L, Roberts TP, Blaskey L, Edgar JC: Resting-state oscillatory activity in autism spectrum disorders. J Autism Dev Disord 2012, 42:1884-1894.

141. Nunez PL, Srinivasan R: Electric fields of the brain: the neurophysics of EEG. 2nd edition. New York: Oxford University Press; 2006.

142. Lachaux JP, Rodriguez E, Martinerie J, Varela FJ: Measuring phase synchrony in brain signals. Hum Brain Mapp 1999, 8:194-208.

143. Duffy FH, Jones K, Bartels P, McAnulty G, Albert M: Unrestricted principal components analysis of brain electrical activity: issues of data dimensionality, artifact, and utility. Brain Topogr 1992, 4:291-307.

144. Duffy FH, Denckla MB, McAnulty GB, Holmes JA: Neurophysiological studies in dyslexia. Res Publ Assoc Res Nerv Ment Dis 1988, 66:149-170.

145. Makeig S, Jung TP, Bell AJ, Ghahremani D, Sejnowski TJ: Blind separation of auditory event-related brain responses into independent components. Proc Natl Acad Sci U S A 1997, 94:10979-10984.

146. Hamm JP, Gilmore CS, Clementz BA: Augmented gamma band auditory steady-state responses: support for NMDA hypofunction in schizophrenia. Schizophr Res 2012, 138:1-7.

147. Carroll CA, Kieffaber PD, Vohs JL, O'Donnell BF, Shekhar A, Hetrick WP: Contributions of spectral frequency analyses to the study of P50 ERP amplitude and suppression in bipolar disorder with or without a history of psychosis. Bipolar Disord 2008, 10:776-787.

148. Clementz BA, Blumenfeld LD: Multichannel electroencephalographic assessment of auditory evoked response suppression in schizophrenia. Experimental Brain Research Experimentelle Hirnforschung Experimentation Cerebrale 2001, 139:377-390.
149. Bosl W, Tierney A, Tager-Flusberg H, Nelson C: EEG complexity as a biomarker for autism spectrum disorder risk. BMC Med 2011, 9:18.

150. Chan AS, Leung WW: Differentiating autistic children with quantitative encephalography: A 3-month longitudinal study. J Child Neurol 2006, 21:392-399.

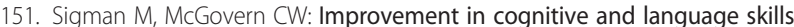
from preschool to adolescence in autism. J Autism Dev Disord 2005, 35:15-23.

152. Qiu M, Li Q, Liu G, Xie B, Wang J: Voxel-based analysis of white matter during adolescence and young adulthood. Brain Dev 2010, 32:531-537.

153. Gray KM, Tonge BJ: Screening for autism in infants and preschool children with developmental delay. Aust N Z J Psychiatry 2005, 39:378-386.

154. Rogers SJ: Diagnosis of autism before the age of 3. Int Rev Res Ment Retard 2000, 23:1-31.

155. Dawson G: Recent advances in research on early detection, causes, biology, and treatment of autism spectrum disorders. Curr Opin Neurol 2010, 23:95-96.

156. Elsabbagh M, Volein A, Csibra G, Holmboe K, Garwood H, Tucker L, Krljes S, Baron-Cohen S, Bolton P, Charman T, et al: Neural correlates of eye gaze processing in the infant broader autism phenotype. Biol Psychiatry 2009, 65:31-38.

157. Percy AK: Rett syndrome: exploring the autism link. Arch Neurol 2011, 68:985-989.

158. Wiznitzer M: Autism and tuberous sclerosis. J Child Neurol 2004, 19:675-679.

159. Bonaglia MC, Giorda R, Beri S, De Agostini C, Novara F, Fichera M, Grillo L, Galesi O, Vetro A, Ciccone R, et al: Molecular mechanisms generating and stabilizing terminal 22q13 deletions in 44 subjects with Phelan/McDermid syndrome. PLoS Genet 2011, 7:e1002173.

160. Knoth IS, Lippe S: Event-related potential alterations in fragile $X$ syndrome. Front Hum Neurosci 2012, 6:264.

161. Musumeci SA, Hagerman RJ, Ferri R, Bosco P, Dalla Bernardina B, Tassinari CA, De Sarro GB, Elia M: Epilepsy and EEG findings in males with fragile $X$ syndrome. Epilepsia 1999, 40:1092-1099.

162. Gorbachevskaia NL, Denisova LV: Brain bioelectrical activity in patients with the fragile X-chromosome syndrome and in their mothers. Zhurnal nevrologii i psikhiatrii imeni SS Korsakova / Ministerstvo zdravookhraneniia meditsinskoi promyshlennosti Rossiiskoi Federatsii, Vserossiiskoe obshchestvo nevrologov [i] Vserossiiskoe obshchestvo psikhiat 1997, 97:33-37.

163. Iznak AF, Gorbachevskaia NL, Zhigul'skaia SE, Grigor'Eva NV, Grachev W, Vasil'Eva AG, Chaianov NV, Gavrilova SI, Roshchina IF, Kolykhalov IV: Quantitative EEG correlates of the human frontal lobe dysfunction. Vestnik Rossiiskoi akademii meditsinskikh nauk / Rossiiskaia akademiia meditsinskikh nauk 2001, 7:48-53.

164. Sabaratnam M, Vroegop PG, Gangadharan SK: Epilepsy and EEG findings in 18 males with fragile $X$ syndrome. Seizure 2001, 10:60-63.

165. Ishizaki A: Electroencephalographical study of the Rett syndrome with special reference to the monorhythmic theta activities in adult patients. Brain Dev 1992, 14(Suppl):S31-S36.

166. Niedermeyer E, Naidu SB, Plate C: Unusual EEG theta rhythms over central region in Rett syndrome: considerations of the underlying dysfunction. Clinical EEG 1997, 28:36-43.

167. Uchino S, Waga C: SHANK3 as an autism spectrum disorder-associated gene. Brain Dev 2013, 35:106-110.

doi:10.1186/1866-1955-5-24

Cite this article as: Wang et al:: Resting state EEG abnormalities in autism spectrum disorders. Journal of Neurodevelopmental Disorders 2013 5:24. 